\title{
Percepção da Estética Facial em Relação ao Tratamento Ortodôntico: Revisão de Literatura
}

\section{Perception of Facial Aesthetics regarding Orthodontic Treatment: Literature Review}

\author{
Graziela Hernandes Volpato*a; Renata Rodrigues de Almeida-Pedrina; Marcio Rodrigues de Almeida; \\ Paula Vanessa Pedron Oltramari ${ }^{\mathrm{a}}$; Thais Maria Freire Fernandes ${ }^{\mathrm{a}}$; Ana Cláudia de Castro Ferreira Conti ${ }^{\mathrm{a}}$
}

a'Unopar, Programa de Pós-Graduação Stricto Sensu em Odontologia, PR, Brasil.

*E-mail: grazi.volpato@hotmail.com

\begin{abstract}
Resumo
A preocupação com a percepção dos pacientes em relação à estética facial evidencia uma mudança de paradigma uma vez que durante o planejamento ortodôntico cada vez mais a opinião dos pacientes tem sido considerada, decisão que no passado era quase que exclusivamente profissional. Com essa mudança, se torna imprescindível quantificar a percepção do próprio paciente em relação à má oclusão e ao comprometimento facial associado a ela, visando estabelecer estratégias de tratamento exequíveis e que contemplam as queixas dos pacientes. Esta revisão de literatura teve como objetivo revisar estudos sobre a percepção da estética facial no tratamento ortodôntico. O desenvolvimento desta revisão foi realizado por meio de plataformas de buscas de pesquisas científicas como: PubMed, Medline e SciElo, utilizando os termos: agradabilidade facial, percepção, e análise facial para seleção dos artigos. Foram encontrados 143 artigos com buscas pelas palavras-chave, porém, 61 artigos envolviam pesquisas na área da cirurgia plástica, psicologia e otorrinolaringologia, sendo excluídos da coleta de dados, 19 artigos não indexados, 22 estudos eram teses e dissertações, no qual também foram excluídos. Por fim, foram incluídos 41 artigos na área da Ortodontia sobre tópicos que contemplavam a avaliação da percepção facial por diferentes avaliadores, assim como fatores que pudessem influenciar nessa percepção. Com base na literatura acerca do tema, pôde-se concluir que vários fatores podem influenciar a percepção da estética facial e que mais estudos devem ser realizados, visando entender as diferentes percepções da estética facial com o objetivo de alinhar as expectativas entre pacientes e profissionais.
\end{abstract}

Palavras-chave: Agradabilidade Facial. Percepção. Análise Facial.

\begin{abstract}
The concern with the patient's facial perception shows a paradigm shift, in which the decision of the treatment plan previously made only by orthodontists today includes more and more the participation of patients. With this change, it is essential to quantify the patient's perception of malocclusion and the facial impairment associated, in order to establish feasible treatment strategies that address patients' complaints. This literature review aimed to evaluate studies regarding the perception of facial aesthetics in orthodontic treatment. The development of this review was carried out by scientific search platforms such as: PubMed, Medline and SciElo, using the terms: facial pleasantness, perception, and facial analysis for the selection of articles. A total of 143 articles were found, however, 61 articles involved research in the field of plastic surgery, psychology and otorhinolaryngology, 19 were non-indexed articles, 22 studies were theses and dissertations and were excluded. Finally, 41 articles in the area of orthodontics were included, which dealt with topics on the assessment of perception by different evaluators, factors that could influence the perception of facial aesthetics. Based on the literature revised on this topic, it was concluded that several factors can influence the perception of facial aesthetics and that more studies should be carried out, aiming to understand the different perceptions of facial aesthetics with the objective to align expectations between patients and professionals.
\end{abstract}

Keywords: Facial Pleasantness. Perception. Facial Analysis.

\section{Introdução}

O conceito beleza é amplo e individual, sendo estabelecido a partir de critérios próprios, o que confere uma natureza extremamente subjetiva ao que é considerado belo. É indiscutível a importância da estética na vida das pessoas, e a aparência facial tem influência na atração pessoal e na autoestima. A face humana é considerada o fator individual mais importante no aspecto de atração (HÖNN et al.,2005).

O critério para se determinar a estética como aceitável ou não, varia de acordo com a sociedade e com valores culturais, e este padrão vêm mudando com a história (SUTTER; TURLEY, 1998). Sendo importante entender que a percepção da estética dentofacial deve ser realizada considerando parâmetros estéticos do paciente e da sociedade ao qual o mesmo pertence (NOMURA et al.,2009, TÜRKKAHRAMAN; GÖKALP, 2004). Essa apreciação da beleza também é influenciada por valores individuais como: sexo, raça, educação e pela influência da publicidade e da mídia (YEHEZKEL; TURLEY, 2004; NGUYEN; TURLEY, 1999). Considerar a satisfação com a face vai muito além das normas. Fatores psicológicos e étnicos influenciam a percepção dos pacientes e devem ser mensurados no momento do planejamento ortodôntico (MANEVSKA et al., 2018). A comparação da percepção estética e satisfação facial entre 
homens e mulheres, adolescentes e adultos também pode ser diferente e merecem atenção (Eslami et al., 2016). A melhora na estética facial e sorriso devem ser objetivos primários do tratamento (BORZABADI-FARAHANI, 2012; JOHNSTON et al., 2005). Considerar a face é importante durante o planejamento do tratamento ortodôntico pois afeta a satisfação dos pacientes com os resultados do tratamento (JUNG, 2016). O desejo de melhorar a estética facial é um fator motivacional e uma das principais razões pelas quais as pessoas procuram tratamento (JOHNSTON et al., 2010).

Baseado nesses conceitos de beleza, a correção apenas da má oclusão isolada não pode ser considerada bemsucedida se a estética facial não for satisfatória ao final do tratamento. A aparência dos dentes e sorriso também são componentes da atratividade facial, e o contorno dos tecidos moles também figura entre os pré-requisitos importantes, tornando-se um passo importante no diagnóstico e plano de tratamento ortodôntico (SARVER, 2015). O panorama atual das pesquisas na área odontológica nos desafia a entender a percepção do paciente em relação a sua aparência sugerindo que o profissional se aproxime das expectativas do seu paciente ao planejar um tratamento (GIMENEZ et al.,2013.) Estudos mostram que existe uma diferença significante quanto à percepção do perfil facial e da aparência dentária entre pacientes e ortodontistas (MONTINI et al., 2007; YIN et al.,2014; DA SILVA GOULART et al., 2019).

Sendo assim, o objetivo desta pesquisa foi apresentar uma revisão baseada nas ferramentas disponíveis na literatura sobre como mensurar a percepção da estética facial, considerando também a satisfação com a aparência dentofacial e as expectativas com o tratamento ortodôntico.

\section{Desenvolvimento}

\subsection{Metodologia}

Foi realizado um levantamento bibliográfico por apenas um pesquisador, no mês de fevereiro de 2020, por meio de plataformas de buscas em base de dados como: PubMed, Medline e SciElo, utilizando as seguintes palavras-chave para seleção dos artigos: agradabilidade facial, percepção e análise facial. Os resumos dos artigos selecionados foram analisados para verificar o atendimento aos critérios de inclusão e exclusão. Foi adotado como critérios de inclusão: artigos publicados sobre o tema que fossem indexados nas bases de dados citadas, artigos envolvendo pesquisas na área da ortodontia que tratavam de tópicos sobre a avaliação da percepção por diferentes avaliadores, fatores que pudessem influenciar a percepção da estética facial e discrepâncias esqueléticas da face. Utilizou-se como critérios de exclusão: artigos que não eram da área da ortodontia, artigos não indexados; teses e dissertações. Considerando as bases científicas analisadas, as referências relacionadas ao tema da percepção e agradabilidade facial em relação ao tratamento ortodôntico atenderam aos critérios de seleção estabelecidos.

\subsection{Resultados}

Foram encontrados 143 artigos com buscas pelas palavraschave, porém, 61 artigos envolviam pesquisas na área da cirurgia plástica, psicologia e otorrinolaringologia, 19 artigos não eram indexados, 22 estudos eram teses e dissertações, sendo, portanto, excluídos. Por fim, foram incluídos 41 artigos na área da Ortodontia sobre tópicos que contemplavam a avaliação da percepção facial por diferentes avaliadores, assim como fatores que pudessem influenciar nessa percepção.

\subsection{Discussão}

\subsubsection{Percepção da estética facial de pacientes, leigos e profissionais}

Ackerman, Proffit e Sarver (1999), já descreviam sobre um planejamento de tratamento em que o ortodontista identificava e quantificava problemas funcionais e estéticos que demandavam correção, reconhecendo estruturas normais e positivas da aparência e do sorriso do paciente que podiam ser preservadas. Durante o exame clínico, não se documentava somente os problemas, mas também os elementos positivos que deveriam ser preservados durante o tratamento.

A medida que os dentistas foram adotando a prática clínica baseada em evidências, foi dado maior ênfase nos valores dos pacientes, como autopercepção da estética facial, expectativa e satisfação com o tratamento ortodôntico.

Tsiouli et al. (2017) sabendo dos questionamentos sobre o impacto clínico das alterações do perfil facial de pacientes após o uso de aparelho funcional, investigaram as alterações faciais percebidas de pacientes Classe II divisão 1 com perfis convexos, após tratamento ortopédico funcional seguido por aparelhos ortodônticos fixos. Fotografias pré e póstratamento de 12 pacientes Classe II divisão 1 tratados com ativadores, 12 pacientes Classe II divisão 1 tratados com aparelhos Twin-block e 12 controles com perfis tratados sem aparelhos funcionais foram apresentados a 10 ortodontistas, 10 pacientes, 10 pais e 10 leigos. Os avaliadores analisaram mudanças na aparência facial em uma escala visual analógica. Não foram encontradas diferenças significativas entre os pacientes tratados com aparelho ativador ou Twin-block. No entanto, o grupo Twin-block diferiu significativamente a partir dos controles também no perfil e alterações do lábio superior, enquanto isso não era evidente para o grupo ativador. Nenhuma diferença significativa foi evidente entre diferentes grupos de avaliadores (ortodontistas, pacientes, pais e leigos). Avaliadores tenderam a perceber mudanças positivas do prétratamento para pós-tratamento principalmente na face inferior e as regiões do queixo. $\mathrm{O}$ tratamento com aparelhos funcionais (ativador e Twin-block) seguido por aparelhos ortodônticos fixos levou a melhoras suaves do perfil, em comparação com pacientes com perfil normal que foram tratados sem aparelhos funcionais. No entanto, essa diferença foi relativamente pequena e clinicamente questionável. Portanto, ortodontistas devem ser cautelosos ao predizer melhora significativa do 
perfil do paciente com essa opção de tratamento.

Um outro estudo também sobre a atratividade do perfil facial de pacientes Classe II tratados com Twin-block foi realizado por O'Brien et al. (2009). Para isso selecionaram 20 pacientes tratados e 20 não tratados, com idades entre 8 e 10 anos, e com um overjet de pelo menos $7 \mathrm{~mm}$. Foram realizadas fotos do perfil no início do estudo e 15 meses após. Silhuetas foram geradas e apresentadas em uma escola do Reino Unido onde foram avaliadas por 30 crianças (com idades entre 10 e 11 anos) e por 24 professores por meio de escala Likert. Os autores puderam observar que o tratamento ortodôntico precoce resultou em melhor percepção da atratividade do perfil facial, visto que, pacientes Classe II tratados receberam melhores notas quando comparados ao grupo controle. O estudo mostrou também que menores valores para o overjet e para o ângulo mentolabial foram associados com perfis mais atraentes.

O fato da estética do perfil facial no tratamento ortodôntico ser subjetiva, torna-se difícil mensurar a melhor maneira de analisá-la. Métodos de avaliação com fotos ou silhuetas auxiliam nesta análise. Hockley et al. (2012) com objetivo de comparar o método mais preciso para estudo do perfil, realizaram uma pesquisa usando fotos e silhuetas do perfil de pacientes afro-americano. Os autores selecionaram 20 adolescentes em início de tratamento ortodôntico sendo 10 homens e 10 mulheres. Utilizaram um software de manipulação de imagem onde obtiveram uma série de sete fotos e sete silhuetas com posições de lábios alteradas em relação a linha-E de Ricketts. Professores de ortodontia e residentes avaliaram os perfis mais agradáveis das séries de fotos e séries de silhuetas de cada paciente. Uma porcentagem de $86 \%$ dos avaliadores preferiu fotografias que estavam dentro da faixa estética aceitável (dentro de $2 \mathrm{~mm}$ da linha-E em qualquer direção) do que as suas preferências por silhuetas (66\%). Os autores observaram também que perfis mais retos, com menos projeção labial, tiveram maior preferência nas silhuetas do que nas fotos.

Reis et al. (2006) fizeram um estudo para determinar as medidas do perfil facial de brasileiros com equilíbrio facial. Fotografias padronizadas do perfil de 50 pacientes foram obtidas. Sobre essas, foram executados os traçados por dois avaliadores, que verificaram vários ângulos, entre eles, $\mathrm{o}$ ângulo da convexidade facial (suplemento do ângulo formado pela intersecção das linhas glabela-subnasal e subnasalpogônio tecido mole, com valor normativo entre $12^{\circ} \pm 4^{\circ}$ ). O ângulo de convexidade facial apresentou a média de $12,32^{\circ} \pm$ 3,93. O estudo observou, entretanto, que indivíduos Padrão I podem apresentar valores do ângulo de convexidade facial tão reduzidos como $4^{\circ}$ ou tão altos quanto $19,5^{\circ}$, sugerindo respectivamente perfis pouco e muito convexos. Dois fatores devem ser considerados: o primeiro é a influência da projeção anterior da glabela na determinação do valor do ângulo de convexidade facial. Uma maior ou menor projeção anterior da glabela pode resultar em uma abertura ou fechamento do ângulo. O segundo fator é a influência do tipo facial na convexidade de indivíduos Padrão I. Em um extremo estariam os indivíduos dolicofaciais, que apresentam uma maior convexidade facial devida à rotação da mandíbula para baixo e para trás, e do outro os braquifaciais, possivelmente portadores dos perfis mais retos entre os indivíduos Padrão I.

Spyropoulos et al. (2001) compararam a diferença de percepção entre leigos e ortodontistas ao analisarem o perfil de pacientes. Utilizaram 20 fotografias de pacientes brancas, com idade média de 11,6 anos. O contorno dos tecidos moles de cada imagem foi digitalizado e as 20 fotografias originais foram alteradas com métodos de distorção. As 20 fotografias iniciais (imagem A), 20 fotografias alteradas com melhoria na estrutura do perfil (imagem B) e 3 fotografias (médias) construídas pela média de todos as 20 fotografias iniciais foram impressas e colocadas em 2 álbuns de fotos. Cada álbum possuía 10 fotografias originais, 10 fotografias alteradas e 3 fotos com imagens médias. Estas fotos foram misturadas e colocadas em ordem aleatória nos álbuns. Um grupo de 10 avaliadores leigos e 10 ortodontistas, foi convidado para analisar a atratividade do perfil facial de cada paciente em uma escala de 0 a 10. Houve uma alta concordância entre os avaliadores, embora os ortodontistas tendessem a ser mais influenciados pelo perfil do que os leigos. Os resultados mostraram que, no grupo dos ortodontistas, houve uma maior correlação entre a foto original e a foto alterada, onde atribuíram pontuações mais altas do que leigos, tanto para a fotografia original como para a alterada. Para faces menos atraente, os ortodontistas não atribuíram pontuações tão baixas quanto aquelas dadas por leigos. As três fotografias médias alcançaram as pontuações mais altas sem diferença entre os grupos de avaliadores. As fotos alteradas foram consideradas mais atraentes do que os originais por ambos os grupos de avaliadores. Conclui-se, portanto, que a melhoria na estrutura do perfil resultou em um aumento da atratividade e que os ortodontistas tendem a dar respostas diferentes dos leigos, embora ambos os grupos de avaliadores concordaram bem com as classificações de atratividade em geral.

Tufekci, Jahangiri e Lindauer (2008) correlacionaram as diferenças na percepção do perfil facial entre leigos, estudantes de odontologia e pacientes de ortodontia. Os participantes (75 cada) responderam a um questionário sobre o próprio perfil. Foram realizadas perguntas de como se sentiam em relação à aparência com seus dentes, com a aparência facial e se estavam felizes com os mesmos. Esta auto-avaliação para atratividade facial foi avaliada em uma escala de 1 a 10 , com 1 representando o menos atraente e 10 o mais atraente. Os participantes também escolheram entre várias silhuetas a que eles achavam mais parecida com o seu próprio perfil. Após a conclusão dos questionários, foram realizadas fotos de perfil dos indivíduos que então foram analisadas por dois ortodontistas para determinar se os sujeitos foram precisos em descrever seu perfil com base nas silhuetas fornecidas no questionário quando comparada com as silhuetas escolhidas. 
Houve uma concordância de 53\% entre as percepções dos ortodontistas e dos indivíduos sobre seus próprios perfis. Concluíram que estudantes de odontologia foram mais precisos na percepção, seguido de pacientes de ortodontia e leigos. Concluíram também que indivíduos que se consideravam com um perfil de Classe II ou III estavam menos satisfeitos com a aparência de seus perfis.

Mcketa et al. (2012) desenvolveram um estudo em que quantificaram as diferenças de percepção de dentistas e de pacientes diante do resultado do tratamento ortodôntico. Tiveram como objetivo, comparar as diferenças de percepção entre eles. A amostra foi composta por 30 pacientes, entre 12 e 40 anos que completaram o tratamento na Universidade de Pittsburgh e que possuíam documentações iniciais e finais completas (fotografias frontais da face com e sem sorriso, fotografias de perfil, fotografias intra-bucais, radiografias panorâmicas, telerradiografias e modelos digitais). Os pacientes avaliaram suas documentações e deram notas para a posição dos dentes, da mordida, do sorriso, para o alinhamento dos dentes e para seu perfil facial. A pesquisa foi realizada na forma de 1 a 5 pontos na escala do tipo Likert. Um grupo de dentistas (cinco ortodontistas, três clínicos gerais e dois protesistas) da Universidade também participaram da avaliação para comparação da percepção do tratamento ortodôntico, onde analisaram todos juntos as fotos dos pacientes projetadas em PowerPoint, com um tempo de 10 segundos por foto. Pontuações iniciais e finais de percepções estéticas e funcionais entre os pacientes e os três grupos de dentistas mostraram diferenças significativas, com os pacientes mais satisfeitos com o resultado de seu tratamento do que os profissionais. Já na avaliação inicial do tratamento, os pacientes tiveram uma maior percepção da estética facial, este resultado foi justificado pelos autores pela tolerância dos ortodontistas para casos complexos. Desta maneira, dentistas devem considerar se essas diferenças justificam a persistência de metas tradicionais de tratamento ortodôntico ou se o planejamento do tratamento deve incorporar a consideração das preferências de cada paciente individualmente para maximizar o tratamento.

Tauk et al. (2016) analisaram a atratividade do perfil facial, com o objetivo avaliar as preferências de ortodontistas, dentistas e leigos. Foram utilizadas para o estudo, duas telerradiografias, sendo uma de um homem e uma de uma mulher e 16 amostras modificadas. As 18 radiografias foram então convertidas em silhuetas e impressas duas vezes: o perfil inteiro (A) e o terço inferior sozinho (B). Nove perfis faciais de ambos os gêneros foram analisados: um perfil original e oito perfis modificados, distribuídas aleatoriamente. Um grupo de 50 ortodontistas, dentistas e leigos, analisaram a estética do perfil de acordo com a Escala Visual Analógica (EVA). Os resultados mostraram que os ortodontistas apresentaram uma correlação muito melhor entre A e B em comparação com os dentistas e mais ainda em relação aos leigos. Os três grupos de avaliadores preferiram os perfis retos ou perfis com protrusão do lábio superior do que perfis com protrusão do lábio inferior. Homens e mulheres tiveram a mesma preferência estética para perfis com valores próximos do normal. Uma comparação de escores de perfil com os coeficientes de correlação mostra que os perfis com as pontuações mais altas apresentam as menores correlações. A observação somente do terço inferior da face não revela a beleza do perfil, por isso é importante usar todo o perfil facial para avaliar a beleza do rosto.

Yin et al. (2014) investigaram as diferenças na percepção do perfil facial e na estética dentária entre adultos jovens chineses e ortodontistas. Uma amostra de 892 chineses, com idades entre 16 e 24 anos, escolheram uma imagem entre cinco silhuetas de diferentes perfis e entre 10 fotos coloridas classificadas de acordo com: o índice do componente estético, o índice de necessidade de tratamento ortodôntico e da aparência da estética dentária, que mais parecesse com seu próprio perfil. Um grupo de 20 ortodontistas repetiram de forma independente o mesmo processo de seleção de imagem. Cada sujeito também respondeu um questionário para psicopatia. Os resultados demonstraram que a diferença de percepção do perfil facial foi significante entre os sujeitos e os ortodontistas. Apenas $37 \%$ dos indivíduos apresentaram perfis retos por avaliação ortodôntica objetiva, mas $85 \%$ escolheram perfis retos pela autopercepção subjetiva. Somente $2,5 \%$ dos sujeitos foram classificados com nota 1 (ideal) por ortodontistas, mas 43,6\% dos sujeitos escolheram a nota 1 (ideal), por autopercepção. Cerca de 17,5\% dos sujeitos, principalmente mulheres, escolheram o perfil levemente convexo como o ideal. Os indivíduos do sexo masculino atribuíram notas significativamente maiores do que as mulheres para a autopercepção do perfil côncavo. Sujeitos com alto grau de psicopatologia atribuíram valores baixos na autopercepção dos perfis faciais. Concluíram que jovens adultos chineses tiveram uma maior autopercepção para perfil facial reto e atraente em relação aos ortodontistas. Uma proporção significativa de jovens adultos, principalmente mulheres, preferiram um perfil facial levemente convexo, também puderam concluir que altos níveis de psicopatia diminuem a autopercepção das necessidades de tratamento ortodôntico.

Barroso et al. (2012) revelaram que os ortodontistas foram capazes de observar avanços mandibulares $\geq 2 \mathrm{~mm}$, enquanto os leigos notaram avanços mandibulares $\geq 4 \mathrm{~mm}$. Paula et al. (2017) observaram que os leigos perceberam melhor o efeito positivo do tratamento com protração mandibular no perfil facial avaliado nas silhuetas em comparação aos ortodontistas.

\subsubsection{Fatores que podem influenciar a percepção facial}

Existe uma discrepância entre as medidas objetivas e subjetivas para avaliação da necessidade de tratamento ortodôntico. Poucas informações qualitativas estão disponíveis sobre percepções dos pacientes em relação a preocupações ortodônticas. Twigge et al. (2016) realizaram um estudo diante das imagens faciais do paciente para avaliar 
as queixas ortodônticas dos mesmos, que são importantes no planejamento. $\mathrm{O}$ estudo foi baseado em entrevistas com 105 adolescentes com idade entre 12 e 17 anos que receberiam tratamento ortodôntico em uma Universidade Pública da Austrália. O rosto de cada paciente foi gravado em vídeo e foram selecionadas três imagens de cada gravação para avaliar as queixas ortodônticas dos pacientes. As principais queixas iniciais foram comparadas com as queixas dos mesmos após avaliarem suas imagens faciais. As queixas também foram comparadas com características oclusais visíveis ao sorrir baseado no Índice de Estética Dental (DAI: dental aesthetic index). Para 37\% dos pacientes adolescentes, imagens do sorriso ajudaram a identificar queixas adicionais. Para $87 \%$ dos pacientes, suas imagens do sorriso os ajudaram a descrever com mais detalhes as queixas. Além disso, alguns pacientes não articularam qualquer preocupação com características mensuráveis no Índice de Estética Dental que eram visíveis ao sorrir. Puderam concluir que quando os pacientes avaliam sua imagem do sorriso, há uma melhor identificação e descrição de suas queixas e que os adolescentes nem sempre estão excessivamente preocupados com a má oclusão visível. Isso pode influenciar o planejamento e o consentimento do tratamento ortodôntico.

Tuncer et al. (2015) com o objetivo de investigar as percepções e expectativas de pacientes jovens, realizaram um estudo envolvendo também os pais dos pacientes. Uma amostra de 491 pacientes com idades entre 14-22 anos e 399 pais, responderam um questionário sobre preferências, necessidades e expectativas sobre o tratamento ortodôntico. A decisão sobre os tratamentos ortodônticos foi influenciada pela sugestão de dentistas. A estética dentária foi o fator determinante para demanda de tratamento para pacientes $(61,0 \%)$ e pais $(57,3 \%)$. A melhora das funções orais foi mais importante para pacientes Classe III do que pacientes Classe I. Não houve diferença entre as classificações de Angle com os resultados encontrados sobre a expectativa e percepção do tratamento. Os pais acharam as fontes de mídia valiosa, porém, a maioria espera obter informações do profissional sobre os tratamentos ortodônticos. O grau de escolaridade de pacientes e pais afetou a decisão pelo tratamento. Puderam concluir com a pesquisa que o desejo pela melhora da estética dentária foi o principal fator motivador para todos os participantes e que os clínicos devem considerar preocupações funcionais de pacientes Classe III durante o planejamento do tratamento. Fatores individuais como gênero, idade e problemas psicológicos, influenciam a percepção dos pacientes diante da expectativa de um tratamento ortodôntico.

Barbosa de Almeida, Leite e Alves da Silva (2019) também investigaram a percepção de jovens brasileiros sobre o tratamento ortodôntico. Vários temas foram analisados sendo que os pontos mais relevantes foram o benefício estético e o impacto do tratamento ortodôntico. $\mathrm{O}$ aspecto negativo mais citado no estudo foi a dor associada ao tratamento, seguido pelo desconforto e trauma causados pelo aparelho fixo.

Em um estudo recente, Amaral et al. (2020) avaliaram a relação entre necessidade ortodôntica tecnicamente definida e a necessidade de tratamento percebida por adolescentes. Houve relação entre a necessidade de tratamento ortodôntico e estética dentária.

Manevska et al. (2018) avaliaram a satisfação com a estética do perfil facial da população croata explorando em que medida os adultos percebem os desvios de um perfil facial equilibrado, diante de uma oclusão normal e seu impacto na satisfação com aparência facial. Este estudo transversal incluiu 225 indivíduos com idades entre 18-42 anos. Os perfis foram analisados por meio de fotografias e foram classificados em três categorias: dentro, abaixo ou acima da faixa padrão para a população croata com uma oclusão normal. Observaram que homens com um perfil côncavo estavam menos satisfeitos com seus rostos do que aqueles com perfil reto ou convexo. Nos homens, a redução do terço inferior da face, o perfil facial desequilibrado, bem como a morfologia do nariz, resultou em um nível mais baixo de satisfação. As mulheres demonstraram uma preocupação estética dentofacial com a redução do terço inferior da face. Concluíram com o estudo que a gama de características faciais aceitáveis é, evidentemente, muito mais ampla do que as normas.

Wezel, Bos e Prahl (2015), analisaram por meio de questionário, a satisfação e a expectativa de pacientes que finalizaram tratamento ortodôntico recente e compararam com os resultados de um estudo realizado há dez anos. Foram encontradas correlações significativas entre a satisfação dentária e as expectativas de tratamento ortodôntico. Os sujeitos do estudo mais recente ficaram mais satisfeitos com a aparência dentária quando comparados aos indivíduos do estudo realizado há dez anos atrás, mostrando que os tratamentos mais recentes satisfizeram mais as expectativas dos pacientes. O fator idade também foi significante, onde observaram que indivíduos com idade igual ou superior a 17 anos apresentaram mais expectativas e satisfação sobre o tratamento ortodôntico.

Para avaliar a percepção estética e a satisfação do perfil facial em homens adolescentes e adultos com diferentes perfis, Eslami et al. (2016) se basearam no ângulo de convexidade do perfil facial (G-Sn-Pog'), onde os pacientes foram divididos em três grupos: perfil reto, convexo, ou do perfil côncavo. $\mathrm{O}$ ângulo de convexidade de $8-16^{\circ}$ indica um perfil reto, enquanto um aumento ou diminuição do ângulo é uma indicação de perfil convexo ou côncavo, respectivamente. Neste estudo transversal, foram avaliados 84 indivíduos de sexo masculino (39 adolescentes e 45 adultos), com perfis reto, côncavo e convexo. O perfil foi projetado no Photoshop ${ }^{\circledR}$ gerando uma silhueta ideal. Outras oito silhuetas representando diferentes relações da maxila e mandíbula foram construídas. Pacientes usaram números de 1-10 para classificar os perfis faciais na ordem de atratividade e escolherem uma silhueta que mais 
se assemelhasse ao seu próprio perfil. Os pacientes foram solicitados a classificar a satisfação com seu perfil diante de um questionário, atribuindo um número de (1-5). Observaram que indivíduos adultos com perfil côncavo apresentaram maior satisfação com o perfil quando comparados aos adolescentes. O prognatismo mandibular caracterizou o perfil menos atraente entre os dois grupos, sendo a biretrusão a silhueta mais agradável na visão dos adolescentes e adultos. Em comparação com a opinião profissional, 42,9\% dos adolescentes e $22 \%$ dos adultos, conseguiram diagnosticar corretamente seu tipo de perfil.

$\mathrm{Na}$ tentativa de estudar os fatores psicológicos, Lin et al. (2016) avaliaram o impacto psicossocial da estética dentária em adultos chineses que buscavam por tratamento ortodôntico, comparando esses adultos com pares pareados que rejeitaram tratamento ortodôntico O Questionário do Impacto Psicossocial da Estética Dental (PIDAQ) foi administrado a 393 adultos, entre 18 e 30 anos. Os participantes foram divididos em dois grupos: um grupo de intervenção (tratamento ortodôntico aceito) e um grupo controle (tratamento ortodôntico rejeitado). A gravidade da má oclusão foi avaliada utilizando o Índice de Necessidade de Tratamento Ortodôntico (IOTN). Observaram que o resultado do impacto psicossocial da estética dentária dos participantes que aceitaram o tratamento ortodôntico foi proporcional à gravidade da má oclusão dos mesmos. Concluíram que esse impacto desempenha um papel importante no processo de tomada de decisão de adultos que procuram tratamento ortodôntico. No entanto, mesmo os adultos com necessidades de tratamento podem rejeitar o tratamento ortodôntico se tiverem pouca autoconsciência do potencial do impacto psicossocial da estética dentária.

Godinho, Gonçalves e Jardim (2020) quantificaram a contribuição do sorriso e de outros componentes faciais para análise da atratividade entre homens e mulheres. Para os homens, o sorriso foi responsável por $49 \%$ da variação da atratividade do sorriso, os olhos em $22 \%$ e o cabelo em $6 \%$. Para as mulheres, $69 \%$ da variação na atratividade facial foi atribuída ao sorriso.

\subsubsection{Percepção facial em relação a discrepâncias esqueléticas}

Knight e Keith (2005) investigaram a relação entre a atratividade facial e as discrepâncias sagitais. Para a pesquisa foram mensuradas a discrepância sagital (ANB) e a altura facial inferior (AFAI) de uma amostra de fotografias de 30 homens e 30 mulheres considerados "padrão" para atratividade facial. Essas fotos foram avaliadas por 6 ortodontistas e 6 leigos em ordem das mais atraentes para as menos atraentes. Concluíram que o valor do ANB, que representa a discrepância sagital, apresentou pouca influência na atratividade facial, mas as faces menos atraentes apresentaram valores de ANB que divergiram amplamente a partir dos valores encontrados nas faces mais atraentes. A AFAI apresentou pouca influência na atratividade facial, mas uma tendência surgiu para as faces femininas: quanto maior o percentual AFAI, menos atraente a face. $\mathrm{O}$ sexo masculino apresentou uma tendência oposta. Os clínicos e leigos apresentaram uma tendência de manter o mesmo padrão de avaliação para as faces mais atraentes.

Com o mesmo objetivo, Johnston et al. (2005) investigaram a influência das alterações do terço inferior da face na atratividade facial na visão dos leigos, por meio da avaliação de dez fotografias manipuladas a partir de um paciente considerado "normal". A altura facial inferior foi alterada para mais e para menos e os 92 avaliadores leigos foram orientados a utilizar a escala visual analógica (EAV) para mensurar a atratividade do paciente, e orientados para responder se procurariam tratamento caso aquela fosse a sua face. Os autores concluíram que as imagens com uma proporção reduzida do terço inferior foram consideradas mais atraentes quando comparadas as imagens correspondentes a um aumento do terço inferior da face. Os indivíduos mais velhos foram menos críticos ao avaliar a atratividade da discrepância esquelética. A maioria dos avaliadores relataram que não iria procurar o tratamento, mesmo para as discrepâncias mais extremas.

Johnston et al. (2010) estudaram a autopercepção da atratividade dentofacial entre pacientes que necessitavam de cirurgia ortognática. Questionários sobre a satisfação com aparência dentária e facial foram preenchidos por 162 pacientes que necessitavam de cirurgia ortognática e 157 pacientes controles. Os resultados mostraram que pacientes cirúrgicos estavam menos satisfeitos com a aparência dentária do que os controles. Mulheres Classe II apresentaram menor índice de satisfação para a aparência dentária. Entre pacientes cirúrgicos, a "forma" e a "proeminência" de seus dentes foram as causas mais frequentes de preocupação. As pessoas mais velhas, as mulheres e os pacientes cirúrgicos estavam menos satisfeitos com a sua aparência facial. Pacientes Classe III cirúrgicos, indivíduos mais velhos e mulheres foram mais propensos a ter mais autopercepção do seu perfil facial. Uma maior proporção de indivíduos Classe II que indivíduos Classe III desejavam mudar de aparência. Os achados indicaram que mulheres e pacientes que necessitam de cirurgia ortognática tiveram níveis mais baixos de satisfação com a aparência dentofacial. Pacientes Classe II exibiram os níveis mais baixos de autossatisfação com a aparência dentária. Algumas evidências de preocupação e conscientização sobre seu perfil facial foram mais pronunciadas entre os pacientes Classe III.

Montini et al. (2007) fizeram um estudo onde avaliaram percepções da mudança do perfil após 5 anos de acompanhamento de pacientes que fizeram cirurgia ortognática. Compararam pares de silhuetas geradas a partir de telerradiografias laterais pós-cirúrgicas de 5 anos, para avaliar se ortodontistas, cirurgiões gerais e leigos percebiam mudanças de perfil resultantes do tratamento ortodôntico cirúrgico e avanço mandibular. Foram avaliados 15 pares de silhuetas. Estas silhuetas incluíram 1 par de controle e 14 pares tratados cirurgicamente, representando avanços mandibulares 
com o objetivo de analisar se as mudanças puderam ser percebidas e se essas mudanças foram esteticamente agradáveis. Observaram que o par de silhueta controle foi identificado por 104 de 127 avaliadores. A grande maioria dos avaliadores foi capaz de identificar mudanças no perfil e características individuais. Houve diferenças significativas entre os grupos de avaliadores. A melhora na estética do perfil foi percebida em 13 dos 14 pares de silhuetas tratados cirurgicamente. A maioria dos ortodontistas, cirurgiões gerais e leigos perceberam mudanças nos diferentes perfis. Uma porcentagem de $89 \%$ dos avaliadores ortodontistas reconheceu a falta de mudança no par de silhuetas de controle, sendo esses valores para os cirurgiões gerais de $78 \%$ e entre os leigos de $76 \%$.

Ryan, Barnard e Cunningham (2012) exploraram por meio de entrevistas, o impacto da deformidade dentofacial e a motivação para tratamento de pacientes ortodônticos cirúrgicos. A amostra foi composta por 18 pacientes ( 8 homens e 8 mulheres), acima de 16 anos de idade que realizariam cirurgia ortognática. Por meio de um questionário, um entrevistador treinado explorou problemas cotidianos de como conviver com a deformidade dentofacial e quanto a motivação para buscar tratamento (incluindo aspectos psicossociais e estéticos). Os pesquisadores observaram que houve uma maior consciência de problemas com os dentes quando comparados com a face. Observaram também que os pacientes notavam problema com os dentes, mas não tinham conhecimento da discrepância esquelética e qual o real problema, sem que um profissional apontasse para eles. Concluíram com o estudo, que a motivação pode não se relacionar com o impacto do problema, mas com uma série complexa de outros fatores, como a personalidade, educação e relacionamentos. Portanto, os clínicos não devem fazer suposições, mas sim explorar esses fatores de forma individual sem ideias pré-concebidas.

Almeida et al. (2010) estudaram diferentes posições da mandíbula na determinação da atratividade facial. A amostra foi composta por fotografias faciais de perfil de uma mulher negra e uma branca, assim como de um homem negro e um branco, selecionados por possuírem uma face harmônica. A partir da face original, as fotografias foram manipuladas no computador, simulando discrepâncias mandibulares por retrusão e por protrusão. As fotografias foram avaliadas por ortodontistas, cirurgiões bucomaxilofaciais, artistas plásticos e leigos, utilizando um álbum fotográfico organizado com as imagens de cada indivíduo inseridas na mesma página e ordenadas aleatoriamente. A escala visual analógica foi utilizada para avaliar a atratividade das fotos. Os resultados demostraram que para as faces do homem negro e para as faces femininas o perfil reto foi o mais aceito. Já para o homem branco, a face levemente côncava foi considerada mais agradável, diferenciando das faces femininas que preferiram perfis convexos. Concluíram que houve concordância entre os grupos de avaliadores na escolha dos perfis mais atrativos. As faces femininas consideradas mais atrativas possuíam o perfil reto, já para as faces masculinas, o perfil levemente côncavo apresentou-se mais atrativo.

Batwa (2018) investigou a influência do tipo facial na avaliação do sorriso e concluiu que o sorriso não deve ser analisado separadamente pois revela percepções distintas dependendo da face do paciente.

$\mathrm{Gu}$ et al. (2017) examinaram a associação entre a atratividade facial frontal e lateral, identificando características anatômicas discrepantes na estética da face. Este estudo identificou uma forte associação entre atratividade facial frontal e lateral. Além disso, discordância entre os escores de atratividade facial frontal e lateral foi detectada na presença de lábio superior fino, nariz convexo e ângulo metocervical curto.

Da Silva Goulart et al. (2019) avaliaram a percepção de leigos e ortodontistas em relação a uma amostra de crianças e adolescente com face longa. Dois terços da amostra avaliada foram consideradas faces longas aceitáveis.

Kanavakis et al. (2019) estudaram a influência do overjet e overbite no perfil de adultos. A correlação com a gravidade de overjet e overbite em toda a amostra foi fraca a moderada. Entretanto, essa associação foi altamente significativa em indivíduos com overjet negativo (prognatismo mandibular).

Esses achados fornecem embasamento científico e segurança ao aspecto estético dos planejamentos ortodônticos, com objetivo principal de prover um tratamento exequível e de satisfação para os pacientes.

\section{Conclusão}

Com base na literatura acerca do tema percepção da estética facial, de uma maneira geral os pacientes e ou leigos apresentam uma percepção da estética facial diferente da visão profissional. Apenas as discrepâncias verticais e horizontais mais severas são percebidas pelos pacientes. Atentos a isso, muitos profissionais poderiam rever os conceitos de necessidades cirúrgicas quando essa correção não for relatada como queixa do paciente. Para um melhor entendimento dessas diferenças de percepção e expectativas, mais estudos podem ajudar a elucidar e entender as diferentes percepções da estética facial com o objetivo de alinhar as expectativas entre paciente e profissional.

\section{Referências}

ACKERMAN, J.L.; PROFFIT, W.R.; SARVER, D.M. The emerging soft tissue paradigm in orthodontic diagnosis and treatment planning. Clin Orthod Res, v.2, p.49-52, 1999. doi: 10.1111/ocr.1999.2.2.49

ALMEIDA, M.D.; FARIAS, A.C.R.; BITTENCOURT, M.A.V. Influence of mandibular sagittal position on facial esthetics. Dental Press J. Orthod, v.15, p.87-96, 2010. doi: 10.1590/S217694512010000200012

BARBOSA DE ALMEIDA, A.; LEITE, I.C.G.; ALVES DA SILVA, G. Brazilian adolescents' perception of the orthodontic appliance: A qualitative study. American Journal of Orthodontics and Dentofacial Orthopedics, v.155, p.490-497,2019. doi:10.1016/j.ajodo.2018.05.020 
BARROSO, M.C.F. et al. The ability of orthodontists and laypeople to discriminate mandibular stepwise advancements in a Class II retrognathic mandible. Prog Orthod, v.13, p.141147,2012. doi: 10.1016/j.pio.2011.12.001

BORZABADI-FARAHANI A. A review of the evidence supporting the aesthetic orthodontic treatment need indices. Prog Orthod, v. 13, p. 304-313, 2012. doi: 10.1016/j.pio.2012.03.003

BATWA,W. The Influence of the Smile on the Perceived Facial Type Esthetics. Biomed Res Int. 2018. doi: 10.1155/2018/3562916

DA SILVA GOULART, M. et al. Evaluation of facial esthetics in long-faced white Brazilian middle school students. Am J Orthod Dentofacial Orthop, v.155, p.812-818,2019. doi: 10.1016/j. ajodo.2018.06.017

DO AMARAL, B.A. et al. Relationship between normative and self-perceived criteria for orthodontic treatment need and satisfaction with esthetics and mastication in adolescents. Am. J. Orthod. Dentofacial Orthop, v157, p. 42-48, 2020. doi: 10.1016/j. ajodo.2019.01.025

ESLAMI, N. et al. Comparison of esthetics perception and satisfaction of facial profile among male adolescents and adults with different profiles. J Orthod Sci, v.5, p 47-51, 2018. doi: $10.4103 / 2278-0203.179406$

GIMENEZ, C.M.M. et al. Cephalometric evaluation of the predictability of bimaxillary surgical-orthodontic treatment outcomes in long face pattern patients: a retrospective study. Dental Press J Orthod, v.18, p.53-58, 2013. doi: 10.1590/s217694512013000500010.

GODINHO, J.; GONCCALVES, R.P.; JARDIM, L. Contribution of facial components to the attractiveness of the smiling face in male and female patients: A cross-sectional correlation study. Am J Orthod Dentofacial Orthop, v.157, p.98-104,2020. doi: 10.1016/j.ajodo.2019.01.022

GU, J.T. et al. Association of Frontal and Lateral Facial Attractiveness. JAMA Facial Plast Surg, v. 20, p.19-23, 2017. doi:10.1001/jamafacial.2017.0710

HOCKLEY, A. et al. Photos vs silhouettes for evaluation of African American profile esthetics. Am J Orthod Dentofacial Orthop, v.141, p. 161-168, 2012. doi: 10.1016/j.ajodo.2011.06.041

HÖNN, M. et al. Perceived relative attractiveness of facial profiles with varying degrees of skeletal anomalies. J. Orofac. Orthop., v 66, p.187-196, 2005. doi: 10.1007/s00056-005-04450

JOHNSTON, C. et al. Self-perception of dentofacial attractiveness among patients requiring orthognathic surgery. Angle Orthod, v. 80, p.361-316, 2010. doi: 10.2319/051209-252.1

JOHNSTON, D. J. et al. The influence of lower face vertical proportion on facial attractiveness. Eur. J. Orthod., v.27, p.349354, 2005. doi: 10.1093/ejo/cji023

JUNG, M. H. Quality of life and self-esteem of female orthognathic surgery patients. J. Oral. Maxillofac. Surg., v.74. p.12401-12407, 2016. doi: 10.1016/j.joms.2016.01.046.

KANAVAKIS, G. et al. Influence of overjet and overbitecon soft tissue profile in mature adults: A cross-sectional population study. Am. J. Orthod. Dentofacial Orthop, v.155, p.57-63.e3. doi: 10.1016/j.ajodo.2018.02.015.

KNIGHT, H.; KEITH, O. Ranking facial attractiveness. Eur. J. Orthod., v.27, p 340-348, 2005. doi: 10.1093/ejo/cji042

LIN, F. et al. Psychosocial impact of dental esthetics regulates motivation to seek orthodontic treatment. Am. J. Orthod. Dentofac. Orthop., v.150, p.476-482, 2016. doi: 10.1016/j. ajodo.2016.02.024
MANEVSKA, I. et al. Satisfaction with facial profile aesthetics: are norms overrated? Int. J. Oral Maxillofac Surg, v.47, p.72-78, 2018. doi: 10.1016/j.ijom.2017.07.024

MCKETA, N.; RINCHUSE, D.J.; CLOSE, J.M. Practitioner and patient perceptions of orthodontic treatment: is the patient always right? J. Esthet. Restor. Dent., v.24, p.40-50, 2012. doi: $10.1111 / \mathrm{j} .1708-8240.2011 .00455 . \mathrm{x}$

MONTINI, R. W. et al. Perceptions of orthognathic surgery patient's change in profile. A five-year follow-up. Angle Orthod, v.77, p.5-11, 2007. doi: 10.2319/061705-206R.1

NGUYEN, D.D.; TURLEY, P.K. Changes in the Caucasian male facial profile as depicted in fashion magazines during the twentieth century. Angle Orthod., v.68, p.872-948, 1999. doi: 10.1053/od.1998.v114.a86137

NOMURA M. et al. Esthetic preferences of European American, Hispanic American, Japanese, and African judges for soft-tissue profiles. Am. J. Orthod. Dentofac. Ortho, v.135, p.87-95, 2009. doi: 10.1016/j.ajodo.2008.02.019

O'BRIEN K. et al. Early treatment for Class II malocclusion and perceived improvements in facial profile. Am. J. Orthod. Dentofacial Orthop, v.135, p.580-585, 2009. doi: 10.1016/j. ajodo.2008.02.020

PAULA ECM. et al. Esthetic perceptions of facial silhouettes after treatment with a mandibular protraction appliance. Am. J. Orthod. Dentofacial Orthop., v.151, p.311-316, 2017. doi: 10.1016/j.ajodo.2016.06.038.

REIS SAB. et al. Análise facial numérica do perfil de brasileiros Padrão I. Rev. Dent. Press Ortodon. Ortop. Facial, v. 11, p. 24-34, 2006. doi: 10.1590/S1415-54192006000600005

RYAN, F.S.; BARNARD, M.; CUNNINGHAM, S.J. Impact of dentofacial deformity and motivation for treatment: a qualitative study. Am. J. Orthod. Dentofac. Orthop., v.141, p.734-742, 2012. doi: $10.1016 /$ j.ajodo.2011.12.026

SARVER, D. M. Interactions of hard tissues, soft tissues, and growth over time, and their impact on orthodontic diagnosis and treatment planning. Am. J. Orthod. Dentofac. Orthop., v.148, p.380-386, 2015. doi: 10.1016/j.ajodo.2015.04.030

SPYROPOULOS, M. N.; HALAZONETIS, D. J. Significance of the soft tissue profile on facial Esthetics. Am J. Orthod. Dentofacial. Orthop, v.119, p.464-471, 2001. doi: 10.1067/ mod.2001.113656

SUTTER, R. E.; TURLEY, P . K. Soft tissue evaluation of contemporary Caucasian and African American female facial profiles. Angle Orthod, v.68, p. 487-496, 1998. doi: 10.1043/0003-3219(1998)068<0487:STEOCC $>2.3 . C O ; 2$

TAUK, A. et al. The importance of using the entire face to assess facial profile attractiveness. Inter Orthod, v. 194, p.1-15, 2016. doi: 10.1016/j.ortho.2015.12.007

TSIOULI, K. et al. Perceived facial changes of Class II Division 1 patients with convex profiles after functional orthopedic treatment followed by fixed orthodontic appliances. Am. J. Orthod Dentofacial Orthop, v.152, p.80-91, 2017. doi: 10.1016/j. ajodo.2016.12.017.

TUFEKCI, E.; JAHANGIRI, A.; LINDAUER, J. Perception of profile among laypeaple, dental students and orthodontic patients. Angle Orthod v. 78, p. 983-987, 2008. doi: 10.2319/102207-503.1

TUNCER, C. et al. How Do patients and parents decide for orthodontic treatment-effects of malocclusion, personal expectations, education and media. J. Clin. Pediatr. Dent., v.39, p.392-399, 2015. doi: 10.17796/1053-4628-39.4.392

TÜRKKAHRAMAN, H.; GÖKALP, H. Facial profile preferences 
among various layers of turkish population. Angle Orthod, v.74, p.640-647, 2004. doi: 10.1043/0003-3219(2004)074<0640:FPPA $\mathrm{VL}>2.0 . \mathrm{CO} ; 2$

TWIGGE, E. et al. Qualitative evaluation of pretreatment patient concerns in orthodontics. Am J. Orthod. Dentofac. Orthop., v.150, p. 49-57, 2016. doi: 10.1016/j.ajodo.2015.12.017

VAN WEZEL, N.A.; BOS, A.; PRAHL, C. Expectations of treatment and satisfaction with dentofacial appearance in patients applying for orthodontic treatment. Am. J. Orthod. Dentofac Orthop, v. 147, p. 698-703, 2015. doi: 10.1016/j. ajodo.2015.01.024

YEHEZKEL, S.; TURLEY, P.K. Changes in the African American female profile as depicted in fashion magazines during the 20th century. Am. J. Orthod. Dentofac. Orthop., v.125, p.407417, 2004. doi: 10.1016/j.ajodo.2003.05.007

YIN, L. et al. Differences in facial profile and dental esthetic perceptions between young adults and orthodontists. Am. J. Orthod. Dentofac. Orthop., v.145, p.750-756, 2014. doi: 10.1016/j.ajodo.2014.01.021 